\title{
Erratum to: Ultrasonographic findings for breast carcinoma with osteoclast-like giant cells
}

\section{Kenichi Sakurai · Katsuhisa Enomoto •} Shigeru Fujisaki

Published online: 14 July 2010

(C) The Japan Society of Ultrasonics in Medicine 2010

\section{Erratum to: J Med Ultrasonics}

DOI 10.1007/s10396-010-0267-6

The legend for Fig. 5 appeared incorrectly and the correct legend is as follows:

Fig. 5 Contrast-enhanced MRI T1 WI shows a highly enhanced tumor

The online version of the original article can be found under doi:10.1007/s10396-010-0267-6.

K. Sakurai $(\bowtie) \cdot$ K. Enomoto Division of Breast and Endocrine Surgery,

Department of Surgery, Nihon University School of Medicine, 30-1 Oyaguchi-Kamimachi, Itabashi, Tokyo 173-8610, Japan e-mail: ksakurai@med.nihon-u.ac.jp

\section{S. Fujisaki}

Department of Surgery, Fujisaki Hospital, Tokyo, Japan 